Article

\title{
The Rock Paintings of Kuh-e-Donbeh in Esfahan, Central Iran
}

\section{Ebrahim Karimi}

Department of Art and Design, Universiti Teknologi MARA Shah Alam, 40450 Shah Alam, Selangor Darul Ehsan, Malaysia; E-Mail: Ebrahim.karimi13@gmail.com; Tel.: +60-17-218-8486

Received: 17 January 2014; in revised form: 6 February 2014 /Accepted: 18 February 2014 /

Published: 26 February 2014

\begin{abstract}
Although a great number of petroglyphs have been identified in Iran, only a few rock painting sites have been found. Despite this, a considerable number of rock paintings have been discovered in Kuh-e-Donbeh, which is a mountain located to the south-west of the city of Esfahan in central Iran. The paintings can be found on the rims of seasonal water channels on this mountain. All the depictions are painted with red pigment sourced from the immediate region. The motifs depicted include zoomorphs, anthropomorphs, horse-riding scenes, and some unknown shapes, etc. A farming theme is also prevalent in the corpus. The paintings are located in five areas and, in some cases, have been subject to intense weathering. Some of the rock paintings may date to the historic period, but reliable dating is not currently possible. So, analysis of the pigments for more secure scientific dating will be required.
\end{abstract}

Keywords: Iran; Kuh-e-Donbeh; rock painting; red pigment; horse-riding; geometric

\section{Introduction}

The rock art of Iran consists of numerous petroglyphs that occur throughout the country, and many sites have been identified where pictograms can be found. The majority of the pictogram sites are, however, located in western Iran. In fact, the history of rock art studies in Iran began with the discovery of rock paintings at the two sites of Mir Malas in Houmian and Docheh, located in Kuhdasht to the west of Iran (Figure 1) [1]. McBurney [2-3] studied the paintings and even conducted some test 
excavations in Mir Malas. McBurney also stated that the Mir Malas paintings are no earlier than the Neolithic or perhaps six to seven thousand years old at most. However, he claimed the depictions of Houmian may be later and some of the paintings from both sites cannot be older than the Bronze Age [2-3].

More recent studies of this region were carried out by an archaeological group under the direction of Marcel Otte [4-5]. This team identified four groups of paintings in the Houmian valley that were displayed on an elongated cliff face with the result that different names were thereby allocated to each collection, including Mir Malas, Houmian, Chowart, and Chalgah Sholah [4]. Further surveys in Houmian led to the discovery of new rock paintings in Sange Mehrdad, Era Remya to the east and west, and Chelga Shalae to the west [6]. The paintings of Mir Malas were studied again by Shirnasabzadeh [7], who classified the depictions and divided them into four types, namely: hunting and fighting themes; zoomorphs depicting ibexes, horses, dogs and fawns; tools; unrecognizable images - probably horsemen or pedestrian hunters carrying bow and arrows, etc. [7].

Eshkaft-e-Ahu, a rock shelter located close to the city of Bastak in southern Iran, was initially studied by Sadeghi [8]. The pictograms of Eshkaft-e-Ahu depict hunting themes that include hunters, zoomorphs, geometric markings and hand-prints [9]. Sadeghi [8] attributed these depictions to the late Epipaleolithic and beginning of the Neolithic with a suggested date of between 8000-6000 BCE, [8]. However, Asadi [9] believes that the pictograms of Eshkaft-e-Ahu may not be older than probably the 1st millennium BC. The pictograms of Cheshmeh Sohrab cave (Mar Awaza), in the Dinwar region located in Kermanshah province in western Iran, were originally discovered by Golzari in 1975 but he did not discuss the pictograms in detail [10]. A more complete report, including a description and interpretation of the depictions, was published subsequently [11]. The pictograms include zoomorphs consisting of ibexes, stags and horses, as well as the portrayal of human forms and horse riding, etc. These depictions are largely painted using white pigment but, in some cases, red pigment was also employed. With regard to the archaeological evidence and iconography, the pictograms at Cheshmeh Sohrab are attributed to the Seleucid (312-64 BCE), Parthian (247 BCE-AD 224) and Sassanid periods (AD 224-651) [11]. In addition, recent research has led to the discovery of new rock paintings in several different regions of Iran. For example, the pictograms of Abdozu, which consist of zoomorphs and geometric marks, are located in Firoozabad in the Fars province and have been dated to prehistory [12]. An archaeological survey, which aimed to identify Palaeolithic sites in the Parishan Lake region close to the city of Kazeroon in Fars province, resulted in the discovery of four caves where Upper Palaeolothic lithic material was also found. The caves are located close to the village of Helak and are referred to by the same name. The fourth rock-shelter, Helak 4, consists of three rock art panels painted using red ochre. One of the panels shows a fish-like image but the other two panels have suffered severe erosion and the motifs are therefore not recognizable [13]. Rock paintings have also been discovered in Tang-e Teyhooee Cave and Tang-e Tadavan Rock shelter in the south of Fars province [14]. Hunting themes and geometric marks made with red pigment represent the most important depictions. The authors Fazel and Alibaigi suggest that an historic timeline may be a more reliable chronology for this rock art [14]. Pictograms have also been reported in North Khorasan province, and three rock art sites consisting of pictograms have been found in north-east Iran at Bash Mahaleh, Zineh Kanloo and Takeh in Nargesloo-ye-Olya [15]. The author Vahdati regards the rock paintings of the Takeh rock-shelter as particularly important and divided them into four groups: 
zoomorphs, anthropomorphisms, depictions of trees, and indistinguishable motifs. Thirty-seven depictions have been identified in Takeh all utilizing red pigment [15]. However, the pictograms of Kuh-e-Donbeh - the focus of the present paper - represent a new discovery of rock paintings, which are located in central Iran rather than in the western regions. Moreover, these newly discovered depictions are located in five sites quite near to one another.

\section{Research Objective and Assessment}

The current research paper is based on data collected from fieldwork carried out in summer 2013. The objective of the research is to identify, document, and describe the rock paintings of Kuh-e-Donbeh in Esfahan, situated in central Iran. It should be added that a lack of personnel prevented the continuation of fieldwork in adjacent mounts and valleys where more rock art sites may exist. Except for Site I, which is situated in a large hollow of the mountain, the sites are located next to seasonal water courses. Photographs have been enhanced using the Dstretch graphic computer program in order to bring out the details of the depictions.

\section{Location of Sites and Geographical Characteristics of the Region}

Kuh-e-Donbeh is located to the south-west of the city of Esfahan, which is the capital of Esfahan province in central Iran (Figure 1). The Atashgah and Sofeh Mountains, which both contain Sassanid remains [16], are located to the north and south-east of Kuh-e-Donbeh, respectively. The north and east of Esfahan consists mainly of deserts, whereas the southern and western areas are made up of the Zagros Mountain range. In order to avoid confusion, it should be pointed out that another mountain is located in Esfahan province known by the same name of Donbeh, which is also referred to as Abolhowl of Esfahan, and is located west of Kuh-e-Donbeh - the mountain which is the focus of the present paper. Esfahan is located 1580 meters above sea level. It lies in a fertile plain made from the alluvial deposits created by the Zayanderood River, which is the most important internal river of Iran [17]. Esfahan is an historic city, and ancient remains dating as far back as the Sassanid dynastic era (AD 224-651) have been identified in the city [116].

\section{The Pictograms of Kuh-e-Donbeh}

Kuh-e-Donbeh consists of five areas within which the pictograms are located (Figure 1). All the paintings use red pigment, which is a substance available throughout the region and can easily be procured at locations near to the sites themselves. The first site is situated in a small depression at the northern side of the mountain, whereas the others are located in the channels on the western side of Kuh-e-Donbeh Mountain (Figure 1). 
Figure 1. Map showing location of Kuh-e-Donbeh and other areas where pictograms can be found in Iran (Google Earth. www.google.com/earth/).

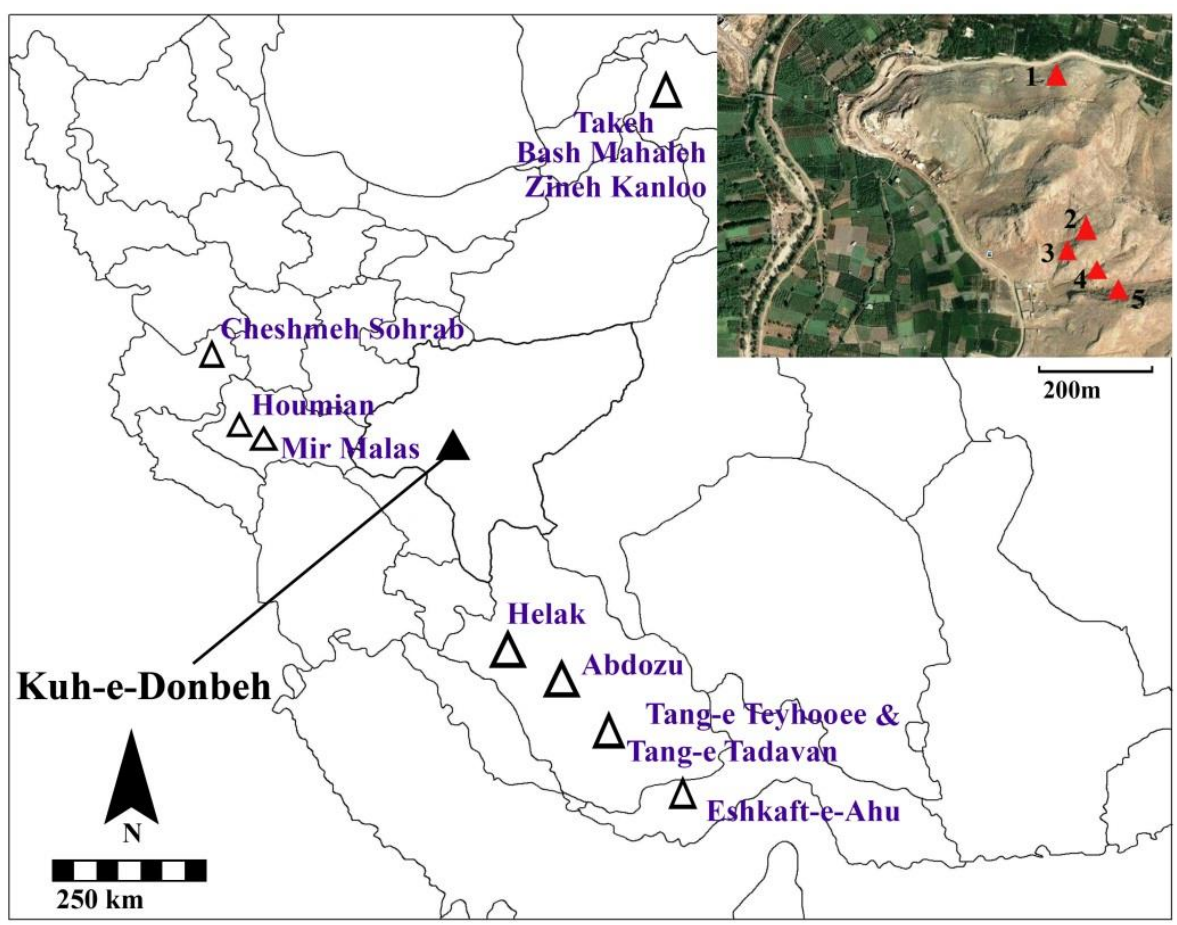

\subsection{Site I}

The pictograms from the first location consist of zoomorphs, anthropomorphs, and an Old Persian inscription in cuneiform but only five of the signs remain (Figures 2 and 3). All the representations were created using red pigment. The first motif represents a human form holding a spear or long stick (Figure 3a). The next portrays an indeterminate zoomorph (Figure 3b). A further group depicts two "ibexes" (Figure 3c), with other scenes depicting two anthropomorphs with an unknown shape directly above which appears anthropomorphic and resembles Farvahar (Figure 3d).

Figure 2. Kuh-e-Donbeh. View of Site I.

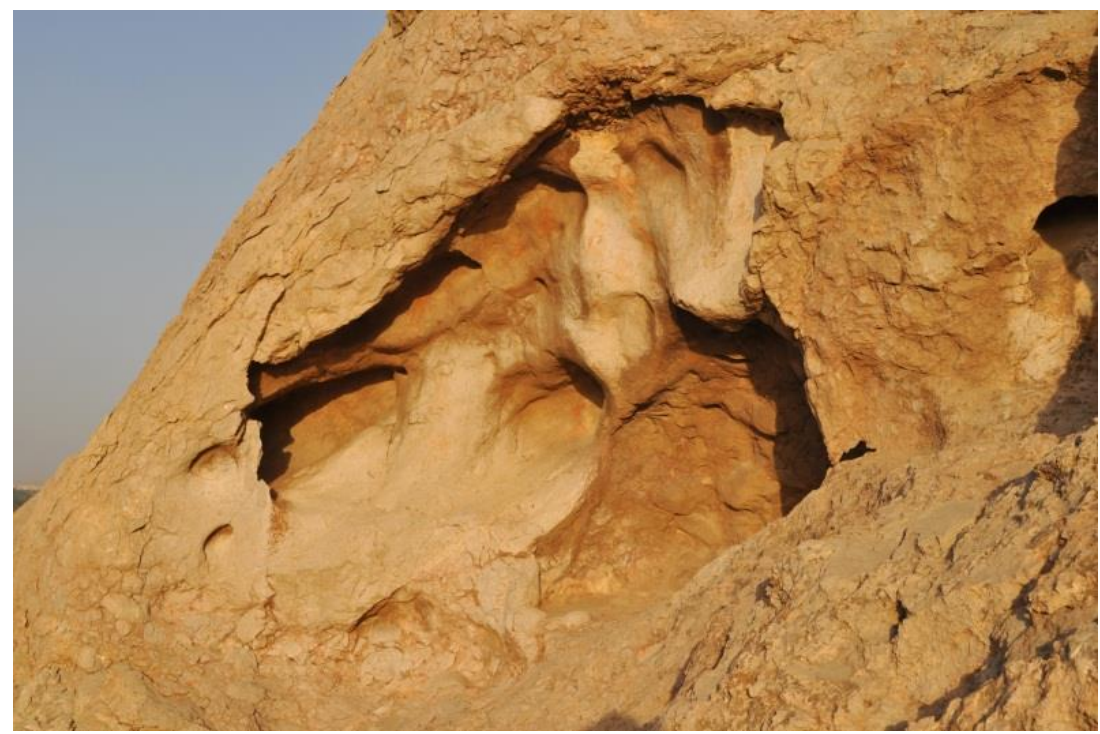


Figure 3. Depictions from Site I: (a) Human shape with a stick-like figure in the hands. (b) An unknown zoomorph. (c) "ibexes". (d) Anthropomorphs with an unknown shape resembling Farvahar above the scene. (e) A cuneiform inscription with an anthropic depiction below the scene. (All photographs enhanced using Dstretch).
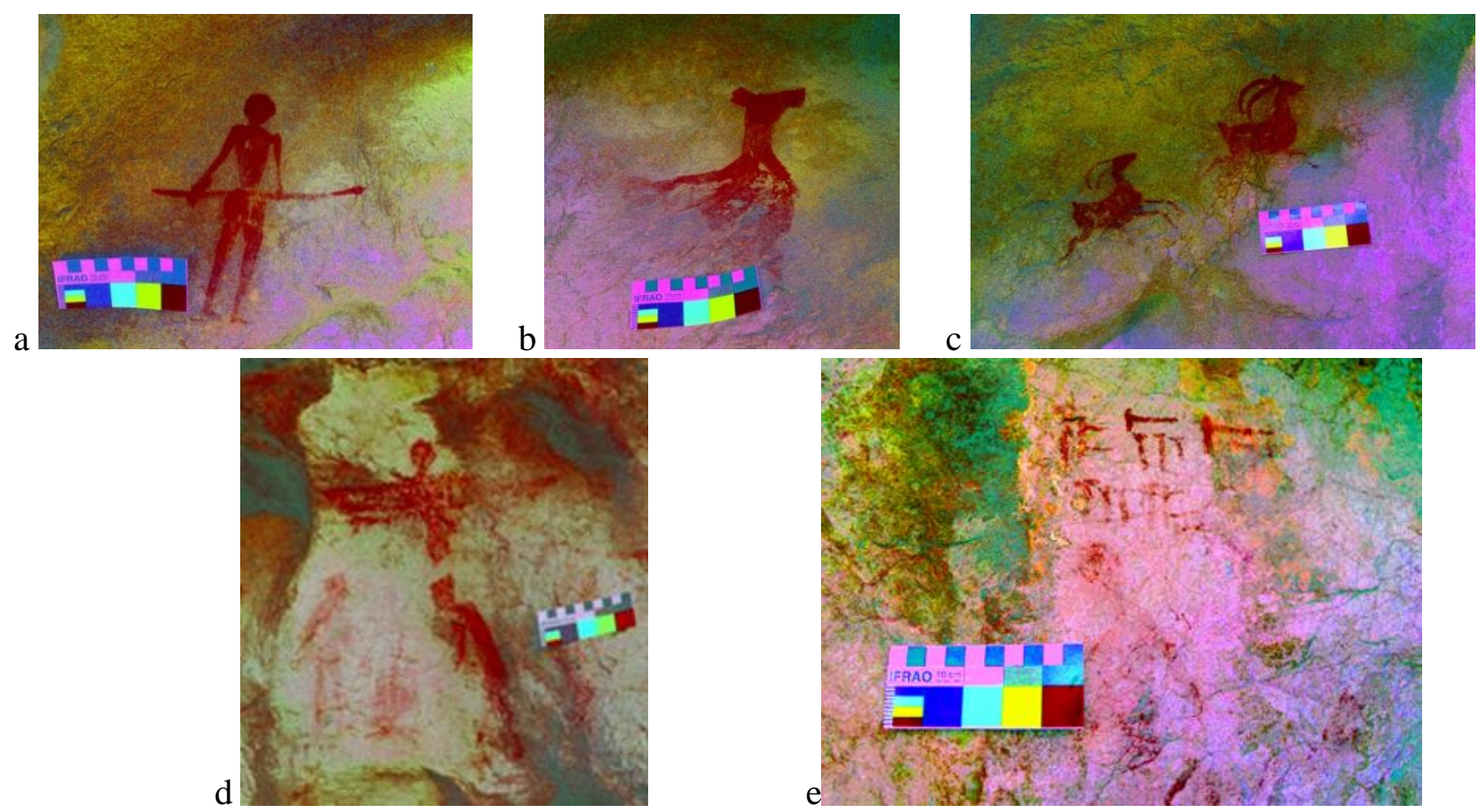

Farvahar is a well-known Achaemenid art symbol that was used for religious purposes in Achaemenid royal inscriptions in Persepolis and Behisotoon, etc. In fact, this symbol has a long history in the Middle East especially in Egyptian and Assyrian art. After the Achaemenid dynasty was established, the symbol became an important emblem in the royal art of the dynasty in that it served as the symbol of Ahuramazda, the great god of the Persians [18]. However, the inverted motif depicted in Figure 3d, which resembles Farvahar, is not clearly discernible and identification therefore remains problematic. The two anthropomorphs depicted standing face to face are probably performing a religious ceremony that may be related to the unknown shape located between the two figures (Figure 3d). The last panel depicts an Old Persian cuneiform inscription (Figure 3e). It seems that further signs may have existed within the inscription of this panel but have now eroded. The Old Persian cuneiform was utilized for the first time around $525 \mathrm{BCE}$ in order to write the Achaemenid royal inscriptions (550-330 BCE) [19], which were written on stone or clay tablets. Nasrollahzadeh [18] suggests the signs do not refer to particular words. Except for the second sign, which signifies an $a$, the other signs are not clear and therefore cannot be considered reliable cuneiform inscriptions and may even have been added to the site more recently [20]. Sampling of the pigments employed to produce the cuneiform signs using new scientific methods may help to determine a reliable date for the inscription. Finally, other anthropomorphs can be found at this site (Figure 3e) but, due to erosion, these remain ambiguous. 


\subsection{Site II}

As already mentioned, there are four areas where pictograms have been found along three channels near to one other (Figure 1). The sites are situated next to watercourses that still flow transiently during the rainy seasons. All the depictions are painted with red pigment that was probably obtained from the local area, as red soil can be found in abundance throughout the region. The first area (Site II) is located above a spring, which still flows (Figure 4).

Figure 4. Kuh-e-Donbeh. General view of Site II.

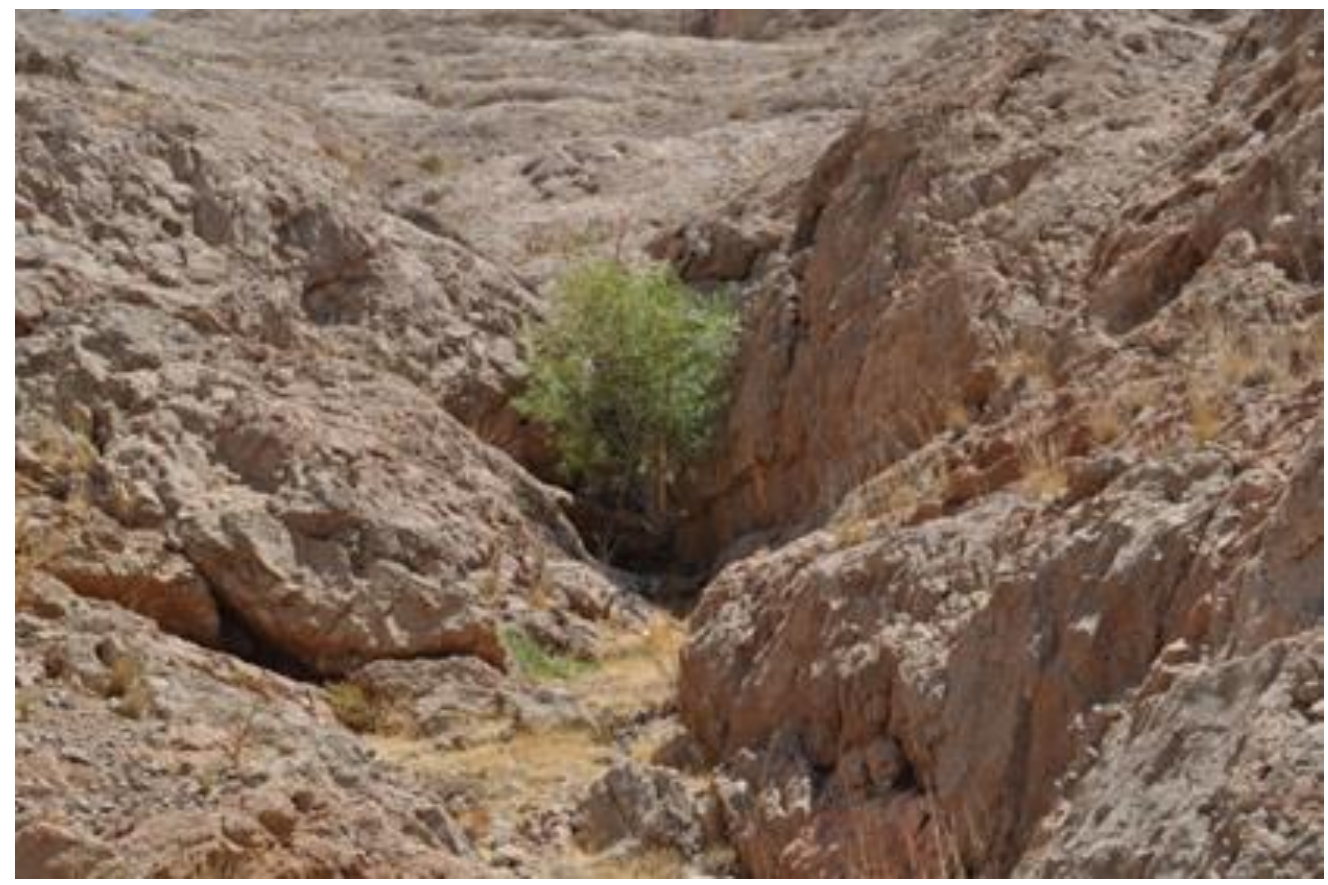

The depictions have now faded probably due to weathering and the action of flowing water during the rainy seasons. Most of the images consist of zoomorphs, probably ibexes (Figure 5a). There is also an unknown shape resembling a flower depicted in a small hollow, which seems to be more recent in age than the other depictions. The image depicted in Figure $5 \mathrm{~b}$ shows an anthropomorphic form to the right carrying indeterminate objects. Interestingly, this image has a parallel with a depiction at Site IV (Figure 12b). Zoomorphs, presumably ibexes or argali sheep, and an indeterminate figure (which seems to depict ploughing and resembles the panel depicted in Figure 19) constitute the other elements in this panel (5a). Unfortunately, due to weathering, these images remain difficult to decipher. 
Figure 5. Depictions from Site II. (a) Zoomorphs (presumably ibexes). (b) Anthropomorphs and an unknown shape, probably a ploughing depiction (both photographs enhanced using Dstretch).

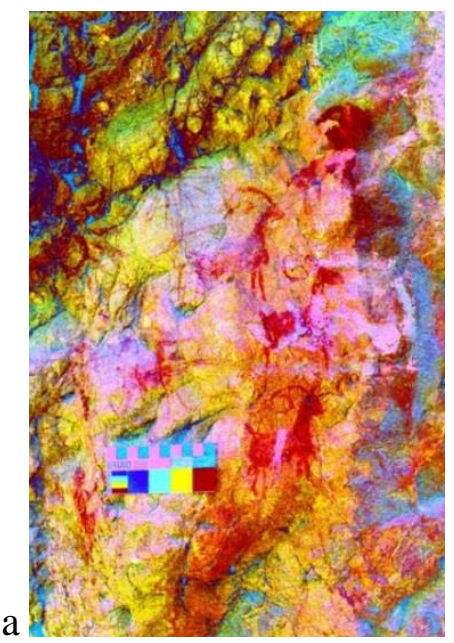

$\mathrm{b}$

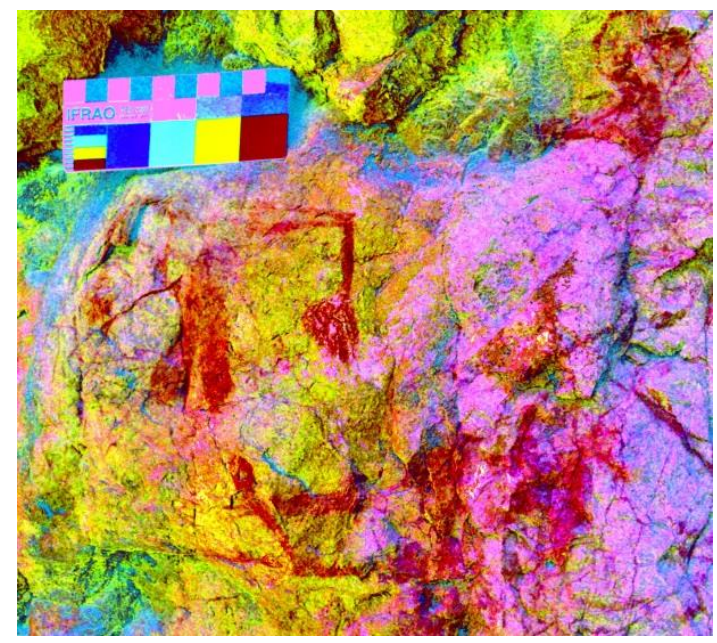

In addition, there is also a petroglyph of a foot as well as an ibex motif engraved at this site, which the locals claim to be of recent age. These motifs are believed to have been made by the local inhabitants (Figure 6).

Figure 6. Engravings consisting of depiction of a foot and ibexes at Site II.
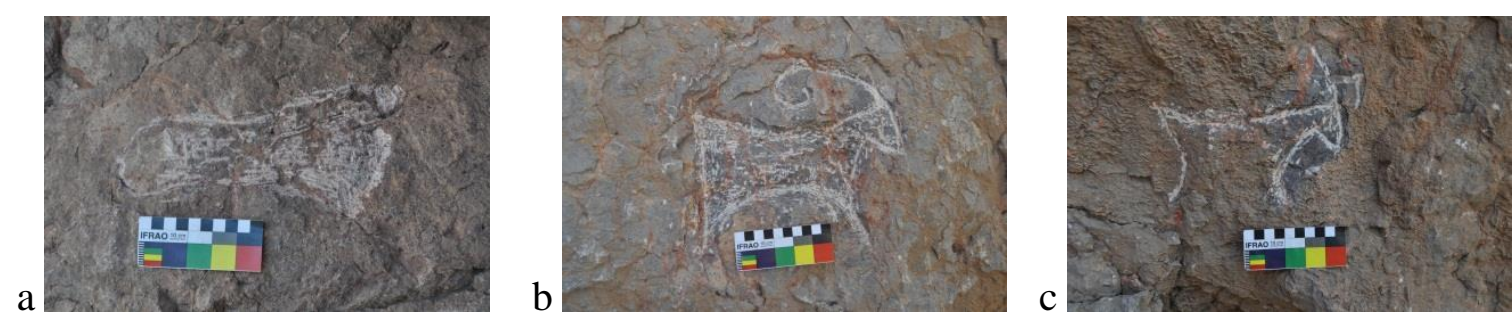

\subsection{Site III}

The next site is located next to the watercourse of the aforementioned spring (Figure 1) but this site contains only one scene situated next to a cave. The scene shows a caravan with four quadrupeds probably dromedaries (one-humped camels) aligned together and tied with a cord. There is also an anthropomorphic figure who seems to be a caravan guard holding the cord to which the camels are tied (Figure 7). 
Figure 7. Kuh-e-Donbeh, Site III. (a) A scene consisting of a caravan with four dromedaries and an anthropomorphic shape, presumably the caravan guard. (b) Same scene enhanced using Dstretch.
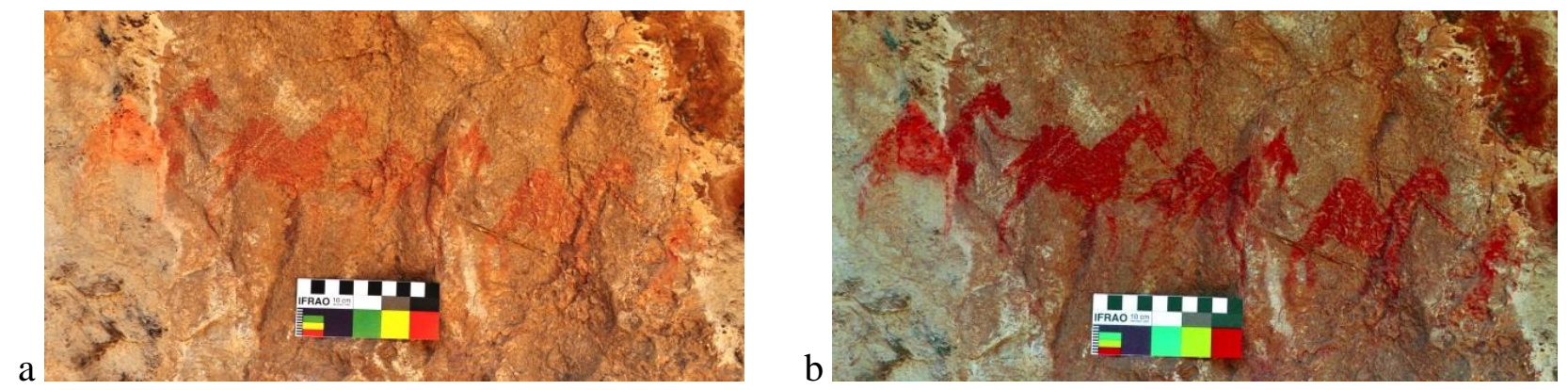

\subsection{Site IV}

All the images at this site (Figure 1) are depicted in red, presumably the same red pigment available from the local region. The site is located at the side of a watercourse, which the locals claim still flows following rainfall (Figure 8). The depictions consist of various motifs, including zoomorphs, anthropomorphs, geometric marks and even a flower.

Figure 8. View of Site IV in Kuh-e-Donbeh.

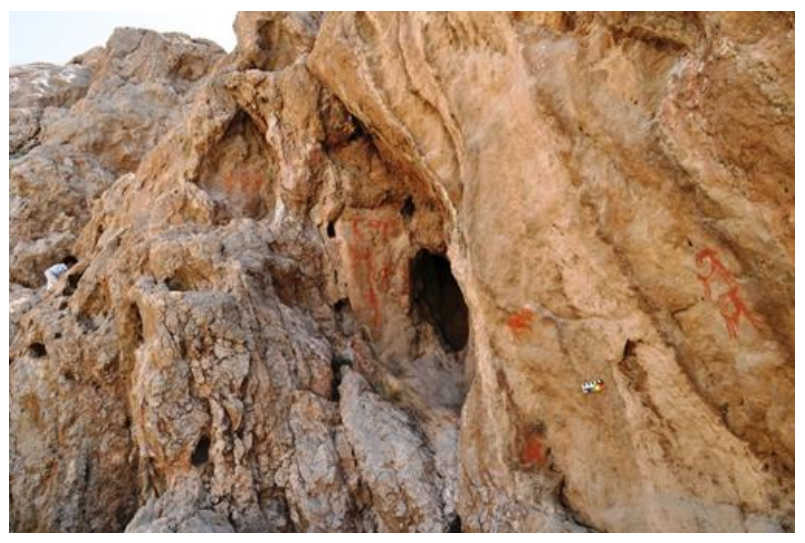

The first panel (Figure 8) consists of four zoomorphs including three "ibexes" and one "zebu", which is now extinct in this region. The ibexes are represented in pairs and one of them seems to be a female. The body of a male is also shown using two lines. Several of the zoomorphs, as well as the sunflower motif (not illustrated), seem to be more recent than the other depictions as recently made motifs benefit from preservation in a location where weathering and the effects of rainfall are prominent. It should also be noted that the ibex is a frequent motif that can be found on the prehistoric pottery of Iran and can even be seen on the pottery of more recent historic periods from the central plateau of Iran [21]. The other zoomorphs depicted at this site are of birds represented in two panels, which all seem to be water birds (Figure 9). In fact, and as mentioned above, this site is located near the Zayanderood River, which has an agreeable environment for various species of water bird and where several kinds of bird continue to exist. 
Figure 9. Kuh-e-Donbeh, Site IV. Water birds.

a
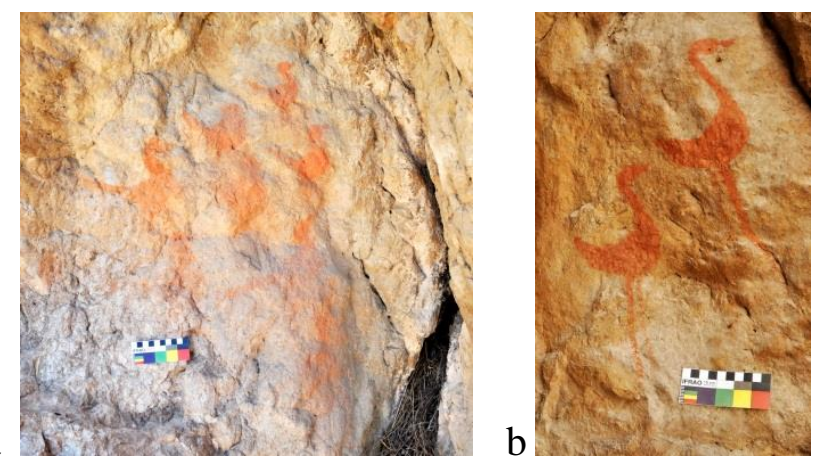

Storks, anatidae, such as duck, etc., represent some of the different birds that live in this region and it is probable that the rock paintings portray these birds. There are also two zoomorphs depicted in a further panel, probably ibexes or deer (Figure 10).

Figure 10. Kuh-e-Donbeh, Site IV. Zoomorphs.

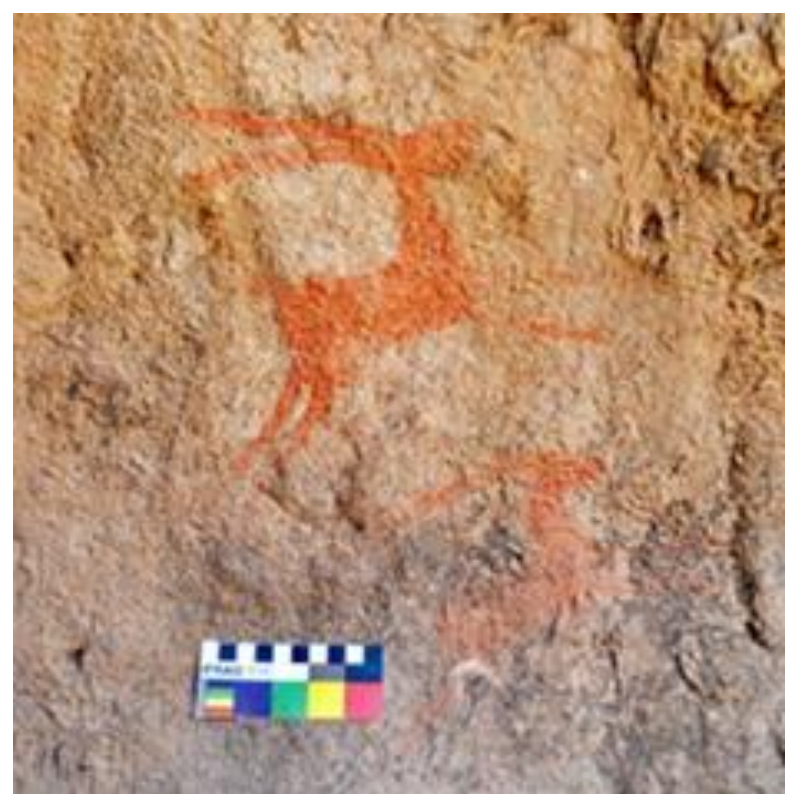

The next panel can be considered the most important scene from any of the sites (Figure 11), which consists of six anthropomorphic forms where two of the upper figures are carrying a shape, which seems to be a zoomorph. The animal form seems to be tied to a stick and is being held on the shoulders of the human figures. The third anthropomorph, depicted to the right in the middle of the scene, is holding something roundish. The final anthropomorph, situated below the others, is holding a linear shape. It should be emphasised that dancing themes can be found on prehistoric pottery from Iran with the oldest identified on a bowl (about 5000 BCE) from Tepe-Khazineh in the south-west of Iran [22]. Groups of dancers can also be found on the pottery of Sialk III (3500-4200 BCE) from central Iran [23]. 
Figure 11. Kuh-e-Donbeh, Site IV. (a) Dancing scene. (b) Same photo enhanced using Dstretch.
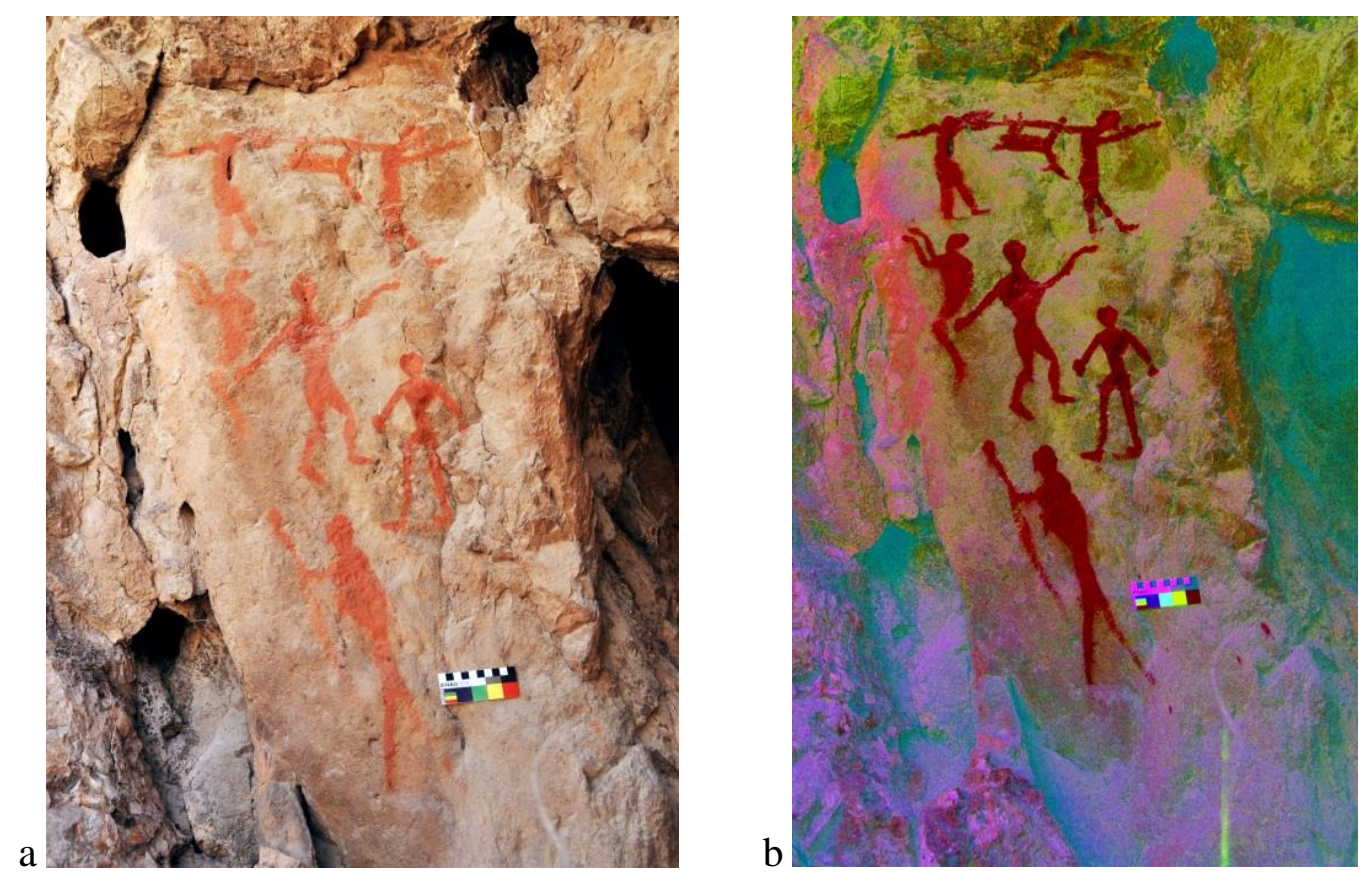

The remaining depictions from Site IV include a geometric motif (Figure 12a) and an anthropomorph holding an object in each hand (Figure 12b).

Figure 12. Kuh-e-Donbeh, Site IV. (a) Geometric mark. (b) Anthropomorphic depiction. (Both illustrations are enhanced using Dstretch).

a
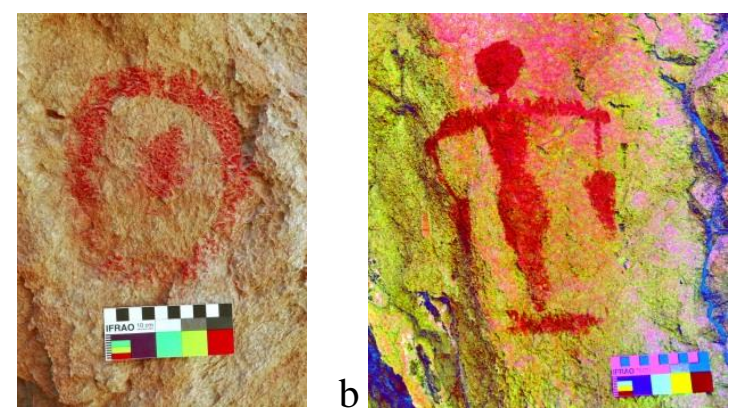

\subsection{Site $V$}

Site $\mathrm{V}$ is located in another channel next to a watercourse about 30 meters to the rear of Site IV (Figure 1). The watercourse was probably originally created by an ancient, now dry, spring. The pictograms, painted in red, are located on the limestone rims situated on both sides of the channel (Figure 13). 
Figure 13. General view of Site V. The depictions were made on the rims of the channel.

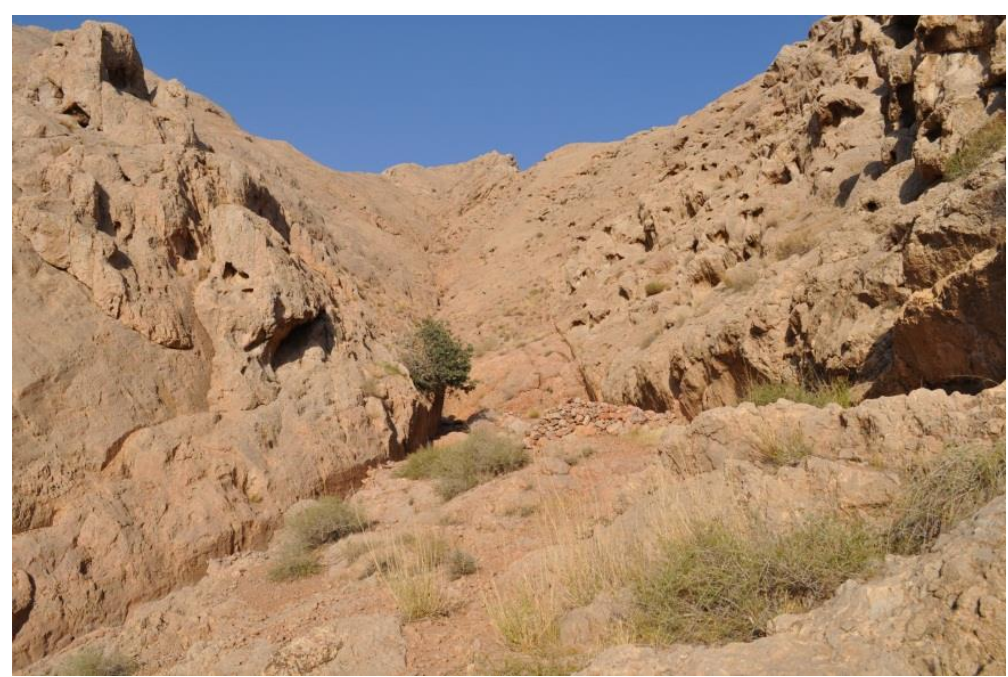

The first scene is situated on the northern face and shows two individuals carrying a quadruped, probably an ibex or a yearling (Figure 14). The animal is tied to a branch or pole as in the scene in the previous site (Figure 11). The depiction presumably refers to a same kind of ceremony but the way the anthropomorphs are depicted is dissimilar and, therefore, probably derives from a different period. The contour lines engraved around the perimeter of the figures depicted in this ancient pictogram seem to have been made more recently.

Figure 14. Site V. (a) Two individuals carrying a quadruped. (b) Same photo enhanced using Dstretch.

a

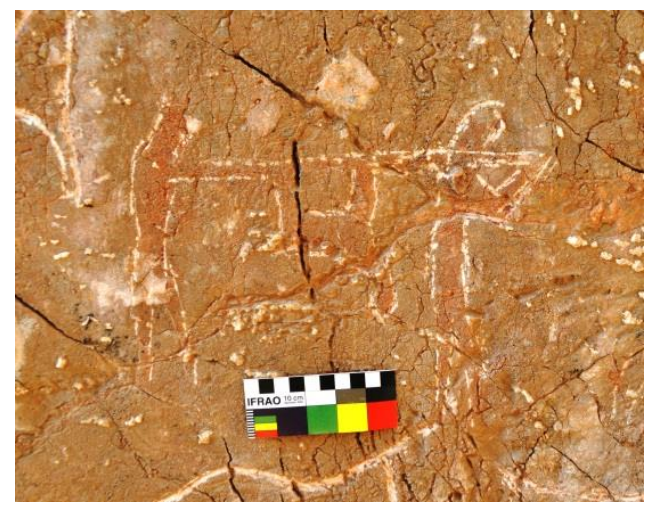

b

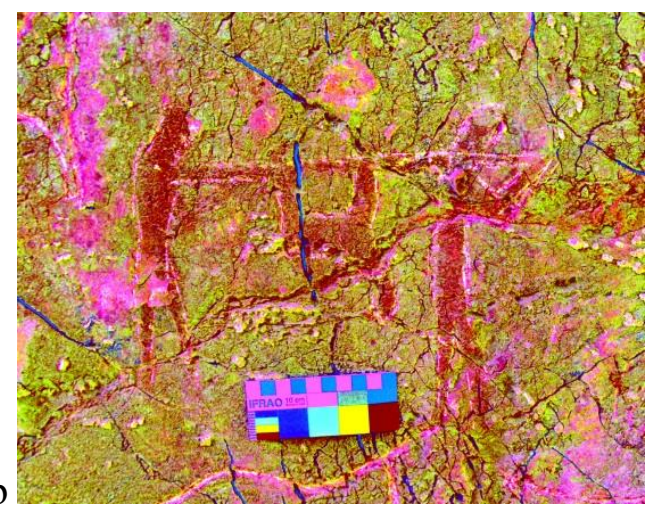

A further anthropomorph, holding what appears to be a bow, constitutes another depiction that can be found on the same facade (Figure 15). 
Figure 15. Site V. (a) Depiction of a human shape. (b) Drawing of the human form based on the photograph.

a
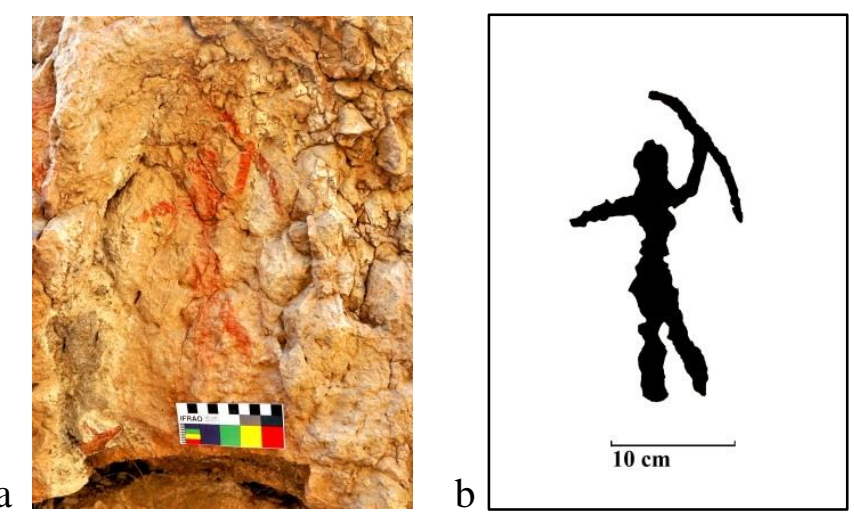

In addition to these depictions, there are also several engravings at the same site which, according to the patination, as well as enquiries made to the local inhabitants, seem to be more recent in age. On further questioning, it was claimed by the local inhabitants that these engravings were indeed created recently by local people without any particular objective or beliefs associated with the petroglyphs. These engravings consist mainly of zoomorphs, such as different kinds of quadruped, probably ibexes, fawns or deer, burros, and zebus - but engraved snakes, fish and water birds are also depicted (Figure 16). Engraved anthropomorphs, such as a shepherd with sheep, a hunter and a herd of ibexes, a petroglyph of a hand, a woman's face, etc. can also be found at this site. The woman's face is accompanied by an engraved date, which shows that the depiction was made 10 years ago (Figures 17 and 19).

Figure 16. Site V. Engravings on the northern side of the channel.
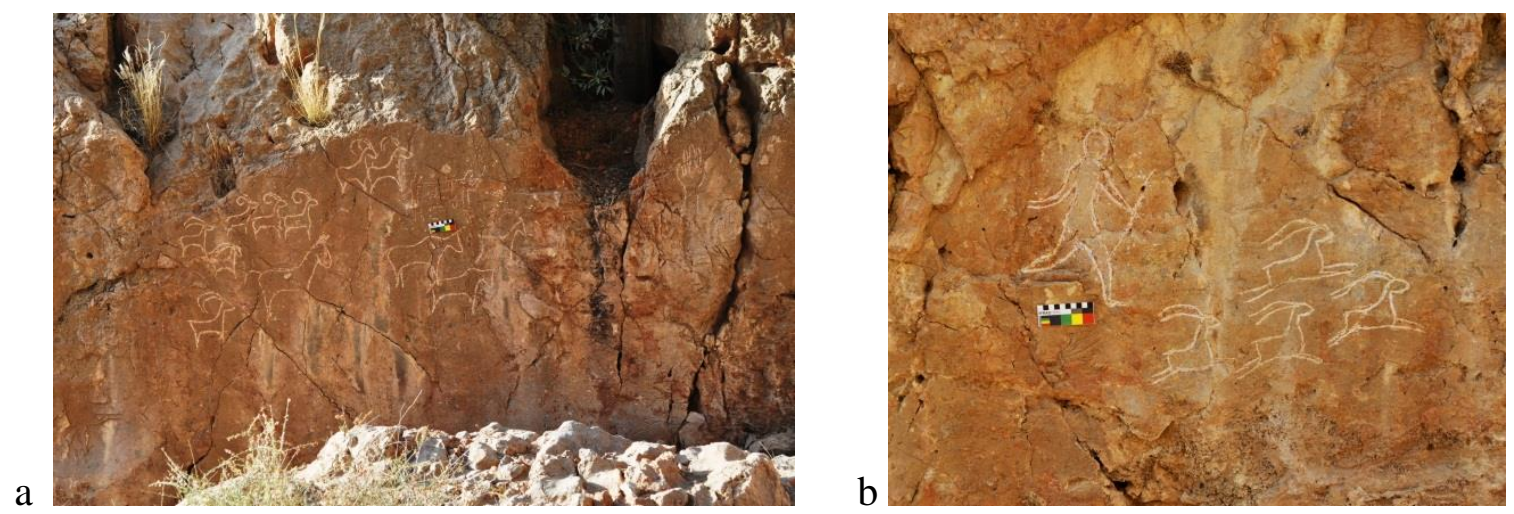

In some cases, however, the recent engravings have been superimposed on previous depictions and have therefore caused damage to the ancient pictograms. The more recent petroglyphs made by local inhabitants engraved over the ancient pictograms can be seen in Figure 17. Three human figures riding horses have also been painted on the rocks of this site and are located above the previous depictions (Figure 18). The horses are galloping and the torsos of the riders have been depicted with a triangular shape, and the reins appear to be thin and the hands quite long. The maximum date of this scene is 2 nd millennium BC when new Aryan immigrants brought horses into the plateau of Iran [24]. 
Figure 17. Site V. Recent engravings superimposed over the ancient pictograms on the southern rim of the channel.

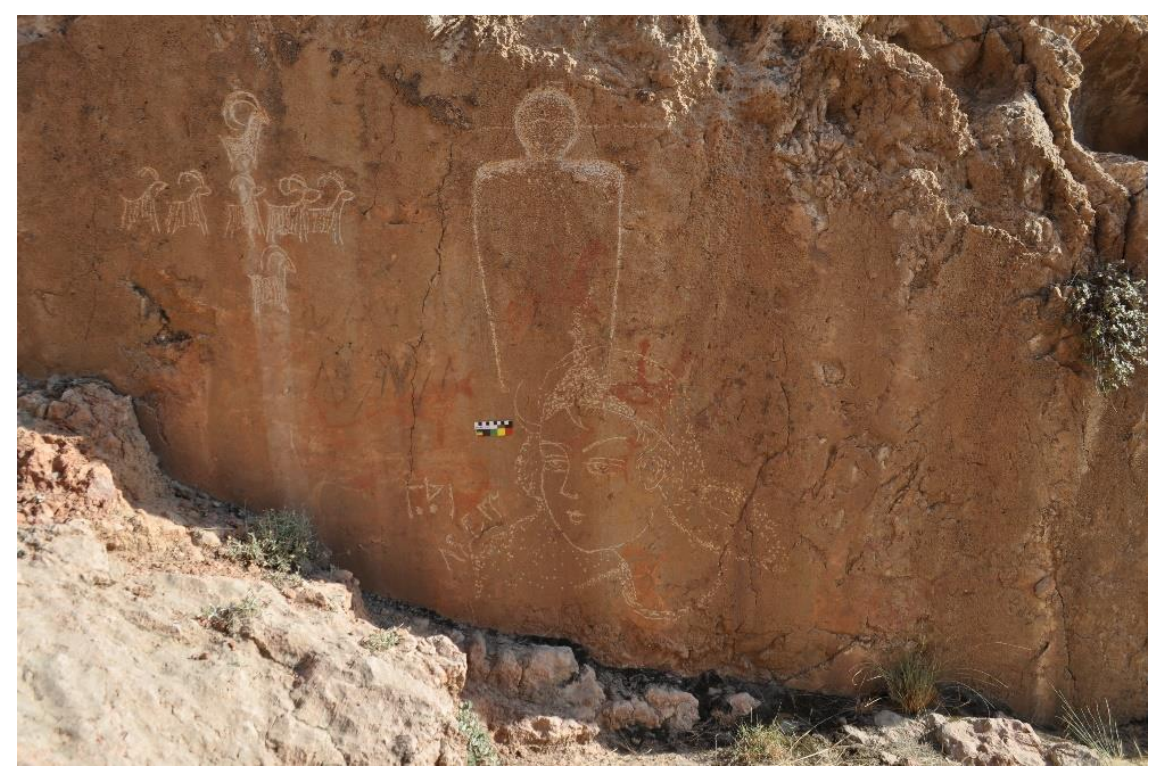

Figure 18. Site V. Painting of horse riders on the northern side of the channel.

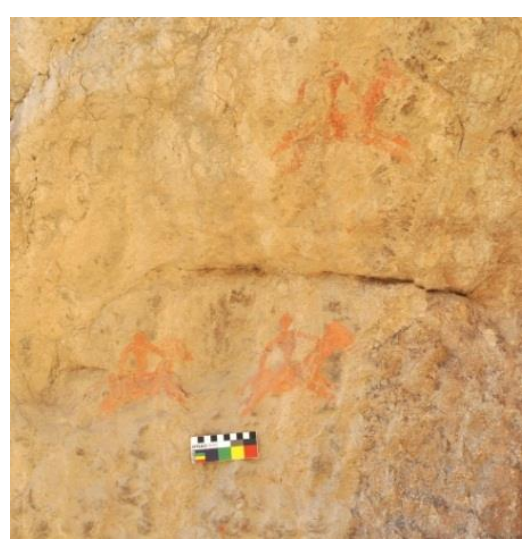

Further panels from this site include several depictions on the southern rim of the channel. In fact, this rim includes two groups of motifs painted alongside one another (Figures 17 and 19). The images to the left of the woman's head show a farming depiction with a plough connected to a zebu. An anthropomorphic figure is also depicted at the rear of the plough with a stick used to direct the animal. These depictions probably show the ploughing of farm land, which is also evident in a further scene (Figure 21) that will be described in due course. 
Figure 19. Site V. A panel consisting of ploughing depiction, horse riders and ibexes (enhanced using Dstretch).

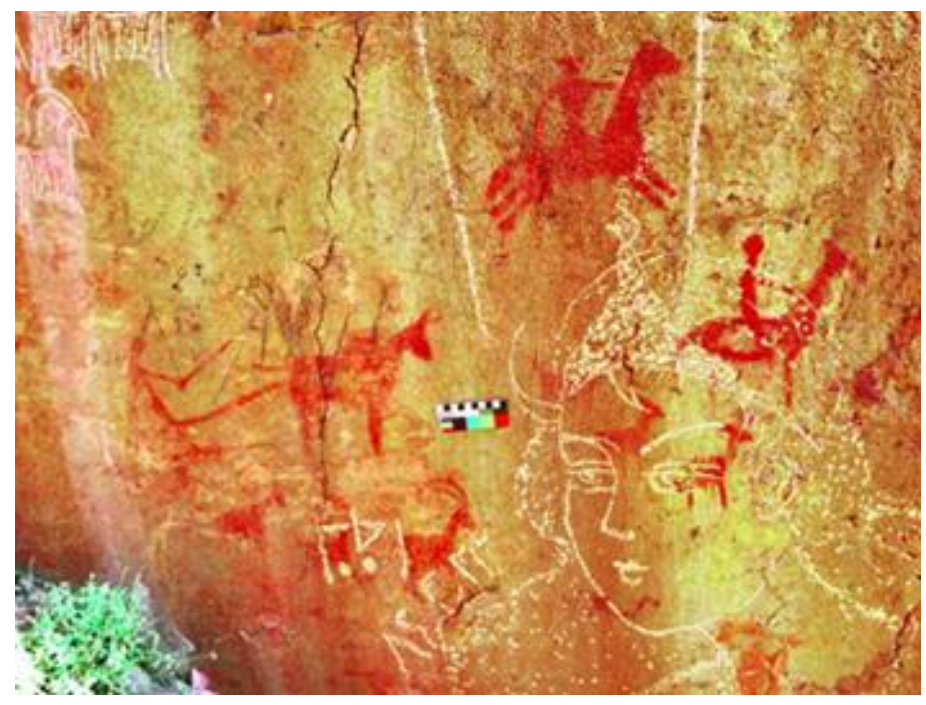

There is also a single "ibex" (not illustrated) that forms the final motif of this part of the site. A further two scenes are depicted in the hollows of the channel. The first includes three human figures, a quadruped, probably a burro, and also a human figure riding a horse to the right of the scene. The human figure, located in the middle of the group, is shown cross-legged slightly raised above the other figures. The other human depictions are holding what appear to be sticks (Figure 20).

Figure 20. Site V. A group consisting of human shapes and a horse rider.

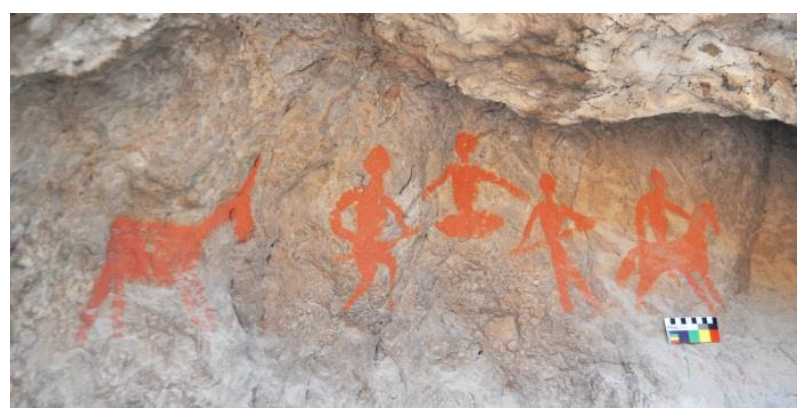

The next panel can be found in a further channel that is located in front of the previous one and is shown in Figure 21. This portrays several anthropomorphic figures where one is using a plough to make a furrow that is being pulled by a quadruped, probably a zebu. Two further individuals holding sticks are depicted situated to the rear of the first figure. Interestingly, there are also two human figures sitting in a cross-legged position depicted in front of the zebu. One is pointing with his or her hand. The second figure is shown with both arms in an open position. Below these various figures, five zoomorphs, probably goats, are depicted together with a further human figure, presumably a shepherd. 
Figure 21. (a) Site V. Ploughing scene and ibexes. (b) Same scene enhanced by Dstretch.
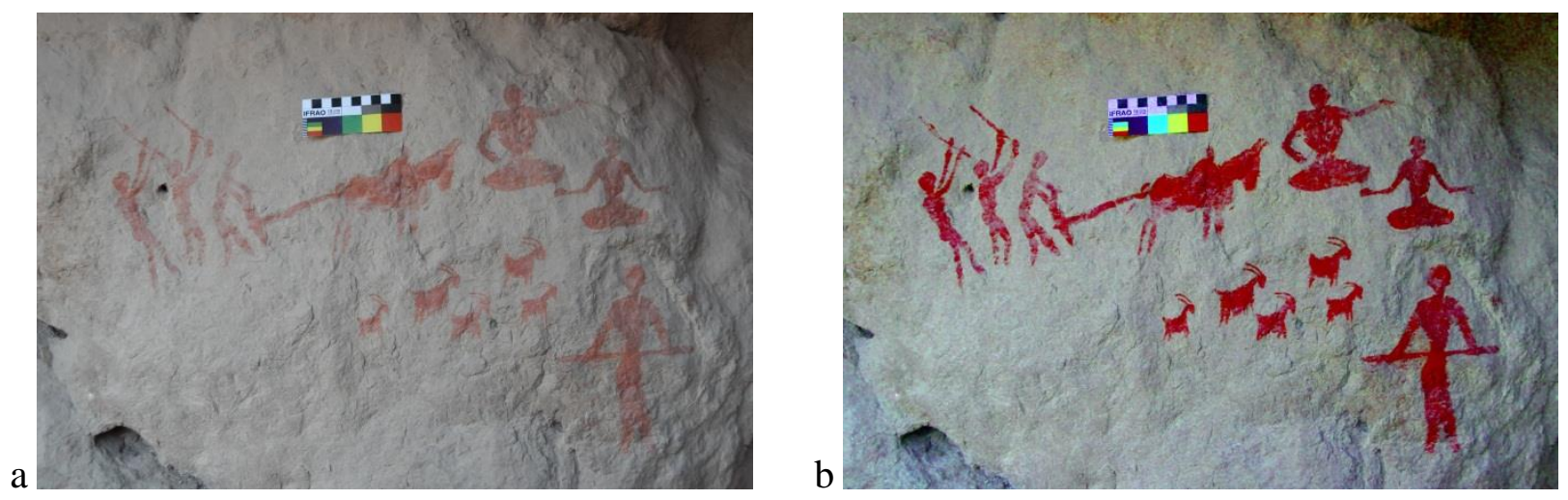

This panel may illustrate a specific religious ceremony performed while farm lands were being furrowed in order to gain fertility and ultimately increase crop yields. The theme of furrowing by plough can be compared to the scene depicted on an Achaemenid seal (Figure 22). Having said this, it should be noted that human figures sitting in a cross-legged position do not exist in Achaemenid art. The scene may therefore even have been made during the Sassanid or Islamic era, which is suggested by the pigment density and level of weathering. It is also possible some of the motifs, such as the human figures to the right of the panel as well as the ibexes, were added to the ploughing scene later. It is significant that the symbol of Farvahar can be seen depicted at the top of this scene, but this seems quite recent in age.

Figure 22. Ploughing scene on Achaemenid seal [25].

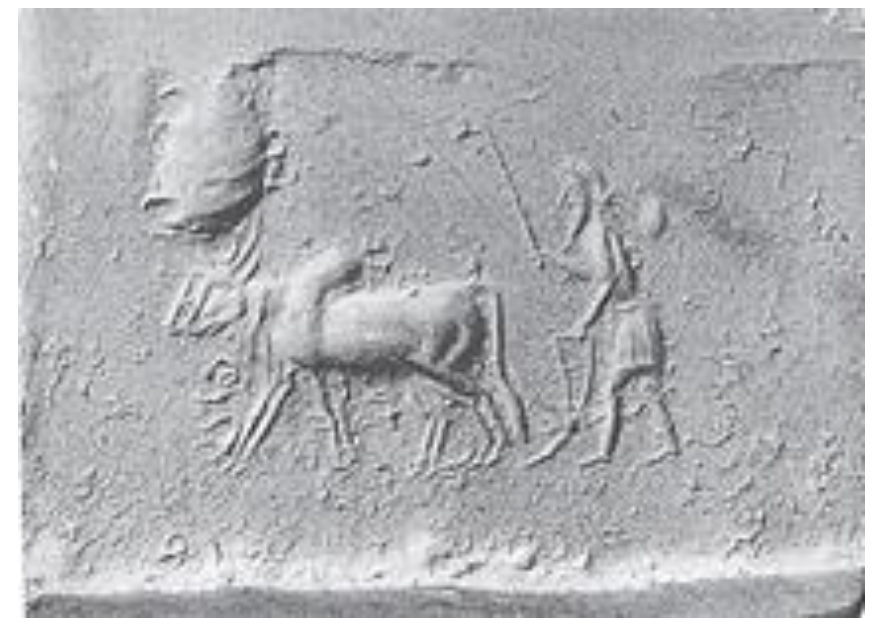

Two more "ibexes" and a painted petroglyph of a human figure holding a stick have also been found in the same hollow but appear to be more recent in age. An ibex and a single person riding a horse constitute the remaining depictions that have been found in some of the small hollows of the channel. 


\section{Conclusion}

The rock art presented above represents the first time such depictions have been identified in the Kuh-e-Donbeh area of Esfahan in central Iran. The paintings were presumably made by a farming community, as several of the scenes illustrate the same subject matter. Concerning the dating of the pictograms, it is difficult to suggest a chronological framework based on art style comparisons, but, with respect to the horse-rider depictions, it should be noted that horses were brought into the Iranian Plateau for the first time in the 2nd millennium BCE by Aryan immigrants. According to the pigment density, paint type and level of weathering, some of the motifs - particularly at Site IV and V-seem to be quite recent in age. However, interviews carried out with the local population confirmed that, except for the engravings, there is no evidence they attempted to draw or paint any new depictions at these sites. It should be observed, however, that the dates suggested above are uncertain and the age of the depictions has to be determined using recent scientific methods. Finally, more fieldwork will be necessary in order to investigate the neighbouring channels of the mountain that may result in the identification of additional pictograms.

\section{Acknowledgments}

I thank Dr Cyrus Nasrollahzadeh for advice on the cuneiform inscription. I also thank Ahmad Kazemian for information regarding the discovery of the sites, and Mehdi Dehghan, a local of the Donbeh region, for help in both finding the pictograms and information about the region. The assistance of Muhammad Mahzuni is also acknowledged. Thanks are also due to Yousef Nadimi for participating in the fieldwork. I would also like to thank the anonymous reviewers and Arts editorial board for their detailed and helpful comments on the manuscript.

\section{References}

1. Izadpanah, H. The paintings of Ducheh Cave in Lorestan. Persian Journal of Archaeology and Art 1969, 3, 53-57.

2. Mcburney, C.B.M. On an Examination of Rock Art Paintings in the Kuh-Dasht Area. Bastan Chenasi va Honar-e-Iran 1969a, 3, 7-9.

3. Mcburney, C.B.M. Report on further excavations in the caves of Kuhi-Dasht area. Bastan Shenasi va Honar-e- Iran (Review of Iranian archaeology and art) 1969b, 3, 8-9.

4. Otte, M.; J. Adeli.; L. Remacle. West Iranian rock art. International Newsletter on Rock Art 2003, 37, 8-12.

5. Remacle, L.; M. Lejeune.; M. Otte.; J. Adeli.; S. Mohammadi. Art rupestre de Houmian, province du Luristan, Iran. Anthropozoologica, Publications Scientifiques du Muséum National d'Histoire Naturelle, Paris 2006, 41(2), 13-27.

6. Remacle, L.; J. Adeli.; M. Lejeune.; S. Mohammadi.; M. Otte. New field research on Houmian rock-art, Luristan Province, Iran. Archaeological Journal of Bastanpazhuhi 2007, 2(3), 9-17.

7. Shrinsabzadeh, F. Rock-Art of Mir Malas, Iran. Canadian Social Science 2012, 8(2), 127-131. 
8. Sadeghi, K. A Historical-technological Survey and Preservation Plan of the Prehistoric Pitograms of Eshkaft-e-Aahouei, Bastak. Unpublished Bachelor Thesis, Art University of Esfahan, 2002.

9. Asadi, A.A. Eshkaft-e Aahou: a rock shelter in Bastac distric, Hormozgan. Persian Journal of Bastanpazhuhi 2007, 2, 65-70.

10. Golzari, M. Kermanshah-Kurdistan (Asad abad, Kangavar, Sahneh) 1. Selseleh Entesharat, National Society of Iran: Tehran, Iran, 1978.

11. Biglari, F.; A. M. Bisotouni.; F. Jamshidi. The Pitogram of Cheshmeh Sohrab Cave (Mar Awaza), Dinwar Region, Kermanshah. Persian Journal of Bastanpazhuhi 2007, 2(3), 50-54.

12. Ghasimi, T.; S. Barfi.; R. Nouruzi. New Found Pitograms from Abdozou Rock Shelter, Firouz Abad, Southern Zagros. Iranian Archaeology 2010, 1(1), 17-26.

13. Nasab, H. V.; Rezaei, M. H.; Naderi, R. Helak, A Palaeolithic cave cpmplex featuring rock art along the northern shore of Parishan Lake, Fars province, Iran. Name-ye Pazhuheshgah, Journal of the Research Institute of I.C.H.T.O 2008, 22/23, 91-96.

14. Fazel, L.; S. Alibaigi. Discovery of cave art in the province of Fars, Southern Iran. Rock Art Research 2012, 29(2), 187-190.

15. Vahdati, A. A. Stone canvases: A preliminary report on the study of two rock-art complexes in North Khorasan province, Northeastern Iran. I.C.H.H.T.O publishing: Khorasan-e-Shomali, Iran, 2010.

16. Zand, A. J. Pre-Islamic Isfahan. Aan publishing: Tehran, Iran, 2001.

17. Shafaghi, S. The geography of Isfahan. Isfahan University Publishing: Isfahan, Iran, 1974

18. Herzfeld, E. E. Iran in the Ancient East: Archaeological Studies Presented in the Lowell Lectures at Boston. (Translated by H. Sanatīzāde). Institute for Humanities and Cultural Studies and Shahid Bahonar University of Kerman: Tehran, Iran, 2002.

19. Abolghasemi, M. Brief history of Persian language. Tahuri Publishing: Tehran, Iran, 2002.

20. Nasrollahzadeh, C. Personal communication, 2013.

21. Masoumi, G. The depiction of ibex on the prehistoric potteries of Iran. Barrasihâ-ye Târikhi, Historical studies of Iran 1970, 4(28), 257-292.

22. Zaka, Y. The history of Dance in Iran. Persian Journal of Culture and People 1965, 16(188), $2-12$.

23. Towhidi, F. Pottery technique and art. Samt publishing: Tehran, Iran, 2000.

24. Makkay, J. Horses. Nomads and Invasions from the Steppe from an Indo-European Perspective. Paper presented at the International Symposium, Archaeology of the steppes, Dipartmentodi Studi Asiatici Istituto Universitario Orientale Series Minor, Naples, 1994, 44, 149-166.

25. Cook, R.S. Achaemenid seals: aesthetics traits, in A. U. Pope and P. Ackerman (eds.) (Translated by N. N. Chegini) A Survey of Persian Art, from Prehistoric Times to the Present, Scientific and Cultural Publishing: Tehran, Iran:, 2007, 7, 124.

(C) 2014 by the authors; licensee MDPI, Basel, Switzerland. This article is an open access article distributed under the terms and conditions of the Creative Commons Attribution license (http://creativecommons.org/licenses/by/3.0/). 